\title{
Coleta de dados em ambientes virtuais: uma possibilidade para as pesquisas em educação
}

Data collection in virtual environments: a possibility for educational research

\author{
Michelle Beltrão SOARES ${ }^{1}$ \\ Laêda Bezerra MACHADO²
}

Resumo: Este artigo visa contribuir para o debate sobre alternativas metodológicas nas pesquisas em educação, situando a discussão a partir das possibilidades de coleta de dados através de ambientes virtuais on-line. Decorrente de uma investigação mais ampla sobre as representações sociais da violência contra o professor na Região Nordeste brasileira, realizada no doutorado em educação, o estudo em questão aborda os instrumentos utilizados para a coleta de dados nas etapas realizadas na pesquisa, dando ênfase às vantagens e desvantagens da utilização dos instrumentos de coleta através da internet. Cabe enfatizar que o avanço das tecnologias da informação e comunicação tem possibilitado que os pesquisadores inovem metodologicamente e desenvolvam pesquisas por novos meios. Conclui-se sobre a pertinência das opções metodológicas consideradas atreladas à questão de pesquisa, aos objetivos e ao modelo teórico utilizado. Tendo isso em vista, afirma-se que, na investigação em questão, a coleta de dados através de ambientes virtuais ofereceu mais vantagens que desvantagens.

Palavras-chave: Metodologia. Coleta de dados. Ambientes virtuais.

\begin{abstract}
This article aims to contribute to the debate on methodological alternatives in education research, situating the discussion from the possibilities of data collection through online virtual environments. Due to a broader investigation of the social representations of violence against teachers in the northeastern Brazilian region, carried out in the doctorate in education, the study in question deals with the instruments used to collect data in the stages carried out in the research, focusing on the advantages and disadvantages of using the collection tools through the internet. It should be emphasized that the advances of information and communication technologies have enabled the researchers innovate methodologically and develop research by new means. We conclude on the pertinence of the methodological options considered linked to the research question, the objectives and the theoretical model used. With this in view, it is stated that in the research in question the collection of data through virtual environments offered more advantages than disadvantages.
\end{abstract}

Keywords: Methodology. Data collection. Virtual Environments.

http://dx.doi.org/10.24024/23579897v28n1a2019p09027

\footnotetext{
${ }^{1}$ Doutora em Educação pela Universidade Federal de Pernambuco, professora da Faculdade Frassinetti do Recife | FAFIRE | e substituta do Departamento de Métodos e Técnicas de Ensino | UFPE | E-mail: michellebssales@gmail.com

${ }^{2}$ Professora Associado 2 da Universidade Federal de Pernambuco - Departamento de Administração Escolar e Planejamento Educacional, atuante na Graduação em Pedagogia, Licenciaturas Diversas e Programa de Pós-Graduação em Educação - Linha de Pesquisa em Formação de Professores e Prática Pedagógica | E-mail: laeda01@gmail.com
}

LUMEN, Recife, v. 28, n. 1, p. 09-27, jan./jun. 2019 


\section{Introdução}

A escolha metodológica do pesquisador deve estar sempre a favor da pesquisa, isto é, cada problema científico tem uma especificidade que determina o processo de investigação em dada realidade. Invalidamos, portanto, a ideia de que a metodologia seria uma mera descrição dos procedimentos técnicos de uma investigação científica e assumimos que a elaboração de uma pesquisa é sempre uma opção, reflete as escolhas, as afinidades e os riscos a serem percorridos pelo pesquisador.

Diferentemente da arte e da poesia que se concebem na inspiração, a pesquisa é um labor artesanal, que se não prescinde da criatividade, se realiza fundamentalmente por uma linguagem fundada em conceitos, proposições, métodos e técnicas, linguagem esta que se constrói com um ritmo próprio e particular (MINAYO, 2001, p. 25-26).

Nesse viés, devemos pensar a escolha dos instrumentos para a coleta de dados de uma investigação, haja vista a diversidade de possibilidades já consagradas em pesquisas científicas: questionários, entrevistas, diários de observação, dentre outros. Em busca de resolver a questão de pesquisa, o investigador pode ir além desses métodos convencionais, reorganizando e adaptando a coleta em prol de seus objetivos. Tudo isso demonstra que pesquisar exige estudo, seriedade, persistência, organização, ética, compromisso social e intencionalidade.

Dessa forma, o objetivo deste artigo é discutir, ainda que não se esgote o assunto, as possibilidades da coleta de dados de uma investigação em educação através de ambientes virtuais on-line. Para isto, situaremos a seguir a pesquisa realizada no doutorado em educação, cuja opção metodológica em questão foi utilizada.

\section{Situando a problemática}

Pesquisas relacionadas à violência no ambiente escolar vêm sendo realizadas, de forma sistemática, desde os anos 1950, e demonstram que este tipo de violência tem sofrido transformações ao longo dos anos. Os conceitos, as modalidades, a frequência e o modo das ocorrências foram se modificando com o passar do tempo. Além disso, o histórico das instituições escolares em nosso país reforça o fato de que situações violentas na escola estão longe de fazer parte de um fenômeno atual.

Os castigos aplicados nas escolas ilustram como os episódios desse tipo de violência foram afetados pelas transformações sociais. Os padres jesuítas no Brasil do século XVI, com seus métodos pedagógicos e disciplinares, autorizavam a punição das crianças para educá-las. Desde então, castigos físicos e psicológicos foram legitimados no ambiente escolar, sendo realizados de diferentes maneiras (uso de palmatórias, repreensão pública, vestimentas vexatórias, etc.) e se tornaram parte da memória coletiva sobre a escola brasileira. De naturalizadas, essas punições foram sendo consideradas agressões que não deveriam pertencer ao ambiente escolar e gradativamente caíram em desuso. 
Os episódios punitivos dentro das escolas ajudam a compreender que a violência se concretiza através do pensamento cotidiano, das relações sociais e das práticas dos grupos de uma determinada cultura e época, além disso, situações envolvendo coerções e agressões físicas nos colégios estão presentes desde o estabelecimento das escolas e de seus métodos pedagógicos no país. Assim, é possível compreender que a instituição escolar é, sobretudo, constituída por indivíduos que imprimem suas trajetórias, representações de mundo e relações sociais.

Com os avanços nas investigações sobre a temática, a violência no interior das escolas passou a ser estudada sob os aspectos sócio-históricos, impressos nas relações de poder, na intolerância que envolve questões morais e cívicas, bem como nas relações estruturais do poderio econômico. Também é abordada a partir dos vieses biológico, psicológico e educacional, com destaque para as patologias, as teorias sobre o desenvolvimento de crianças e adolescentes e a didática. Portanto, esse tipo de violência se estabelece como um fenômeno complexo, indissociável do indivíduo nos planos biopsíquico e social.

Ainda, Osório (2007) aponta que a violência está ligada a representações sociais que a codificam de forma positiva ou negativa de acordo com determinado tipo de acontecimento ou referências que as admitam ou não. Essas colocações apoiam a ideia de que o conceito de violência, apesar de ter elementos comuns, é reconstruído conforme as respectivas especificidades sociais (cultura, política, valores, dentre outros) de determinada localidade ou instituição.

De fato, quando se fala da violência escolar quase sempre vêm à tona os casos ocorridos entre os alunos ou contra eles, quais sejam punições, evasões, brigas e principalmente o bullying. Porém, tem sido comum nas escolas professores confiscarem armas de fogo, as chamadas armas brancas (facas, punhais, dentre outros), drogas e outros artefatos que são utilizados para coerção deles próprios em seus ambientes de trabalho. Dentre as modalidades da violência ocorrida no ambiente escolar, este trabalho tomou como objeto de estudo a violência contra o professor.

É alarmante constatar que professores fazem parte das estatísticas de um quadro em que são baleados, esfaqueados e, nos casos mais extremos, assassinados em seus ambientes de trabalho. Um caso ocorrido em uma escola pública municipal de São Paulo, em setembro de $2011^{3}$, é um exemplo: um estudante de 10 anos atirou contra a professora na sala de aula e depois cometeu suicídio. Outro dado que chama atenção é que pais de alunos também são apontados como agressores, como em um episódio ocorrido em Caruaru-PE, em outubro de 2010, em que uma professora foi agredida por um pai de aluno em uma reunião de pais e sofreu traumatismo craniano ${ }^{4}$.

\footnotetext{
${ }^{3}$ Disponível em <http://noticias.uol.com.br/ultimas-noticias/efe/2011/09/22/aluno-de-10-anos-dispara-contra-professora-e-se-suicida-em-escola-paulista.jhtm>

${ }^{4}$ Disponível em <http://ne10.uol.com.br/canal/interior/agreste/noticia/2010/10/23/diretora-de-escola-sofre-traumatismo-craniano-ao-ser-agredida-por-pai-de-estudante-241244.php>
} 
Casos como estes são noticiados em diversas partes do mundo. Na Alemanha, em novembro de 1999, um estudante de 15 anos matou a facadas seu professor depois de aceitar uma aposta de 500 dólares feita com colegas ${ }^{5}$. Nos Estados Unidos, numa escola da cidade de Harrold, no norte do Texas, os professores trabalham armados, dentro das classes, desde $2008^{6}$.

Abramovay \& Rua (2002) delinearam um quadro da violência enfrentada pelos docentes nas escolas no Brasil: dos alunos que têm arma de fogo, $70 \%$ já levaram seus revólveres para a escola; as ameaças contra professores tornaram-se mais constantes e perigosas: $50 \%$ do corpo docente de São Paulo e 51\% de Porto Alegre relataram algum tipo de agressão; e quatro de cada dez professores atribuem a violência ao envolvimento com drogas por parte dos alunos.

Tomar conhecimento desta realidade enfrentada pelos docentes impulsionou nossas pesquisas sobre a temática. Já no trabalho de conclusão do curso de graduação em Pedagogia, em 2010, buscamos compreender como professores da rede particular e pública da Região Metropolitana do Recife (RMR) conceituavam e enfrentavam este tipo de violência em suas salas de aulas. Os resultados indicaram que os professores, além de a considerarem multifacetada, não sabiam lidar com a violência contra eles de forma mais efetiva. Os estudos sobre o tema continuaram no mestrado em educação, em 2011, no qual, utilizando como aporte a Teoria das Representações Sociais, buscamos captar como docentes de escolas públicas e privadas de Recife compreendiam essa violência contra eles. Os achados dessa pesquisa revelaram novamente a fragilidade dos professores, tanto em relação aos episódios de violência que enfrentavam corriqueiramente em seus ambientes de trabalho, quanto na falta de investimento das autoridades governamentais, dos cursos de formação docente, de investigações na área educacional, das instituições escolares e da sociedade de maneira geral, sobre a violência contra esses profissionais nas escolas.

Os resultados obtidos nestas investigações situaram a violência no ambiente escolar como um dos elementos que provoca o adoecimento dos professores, principalmente porque explicita o descompasso entre as exigências e demandas colocadas pela sociedade para a escola e, consequentemente, para os docentes. Estas constatações suscitaram o desejo de dar continuidade aos estudos sobre a temática no curso de doutorado em educação, dessa vez abordando uma instituição que se espera estar preocupada com os diferentes mecanismos que afetam o professor da escola básica: os sindicatos docentes, bem como seus associados. Assim, voltamos nosso olhar para as entidades de proteção aos professores na Região Nordeste brasileira, que, apesar de ser conhecida pelas belezas naturais, compreende problemas sociais históricos relacionados a saúde pública, precariedade dos serviços de saneamento básico, altos índices de violência, e defasagens educacionais de diferentes ordens. Portanto, o presente trabalho considerou

\footnotetext{
${ }^{5}$ Disponível em: < http://www1.folha.uol.com.br/folha/mundo/ult94u40602.shtml>

${ }^{6}$ Disponível em: <http://noticiasdescola.blogspot.com.br/2008_08_01_archive.html>
} 
a violência contra o professor a partir das principais associações sindicais nordestinas, seus dirigentes e associados.

Na obra O mal-estar docente: a sala de aula e a saúde dos professores, Esteve (1999) deixa claro que, diante desse contexto social de mudanças, os professores se sentem insatisfeitos por não conseguirem cumprir, com excelência, as exigências de sua profissão e nem reverter a situação precária em que se encontram. Isto pode ocasionar tanto uma crise de identidade profissional, quanto doenças físicas e psíquicas. A violência contra o professor se afirma, portanto, como um objeto de estudo que deve ser aprofundado, para que seja possível a elaboração de estratégias de enfrentamento e prevenção.

Valores que sustentaram a produção contemporânea da profissão docente, como o modelo proposto pelo movimento escolanovista, no qual a ação do professor deveria conjugar os méritos das ciências do comportamento e da aprendizagem às virtudes de uma ética da pessoa, de sua autonomia e de sua dignidade, estão em constante discussão frente às diversas mudanças sociais e transformação dos sistemas educativos. Em 1999, Nóvoa já alertava que os grandes ideais estabelecidos na antiga era escolar necessitavam de ser reexaminados, pois já não serviam de norte à ação pedagógica e à profissão docente (NÓVOA, 1999, p. 28).

Por esses motivos, Tardif (2014) afirma que não mais existe a crença de uma conexão fundamental entre os saberes escolares e os saberes necessários à renovação das funções sociais, técnicas e econômicas. Assim, os saberes transmitidos na escola não parecem mais corresponder aos saberes socialmente úteis no mercado de trabalho. Essa inadequação sugere também a desvalorização dos saberes transmitidos pelos professores e dos saberes escolares em geral, cuja pertinência social não é mais tida como óbvia (TARDIF, 2014, p. 47).

A partir dessas premissas, constituiu-se a pergunta norteadora da investigação: como um fenômeno que tem estado na pauta diária do professor "violência contra si" povoa o universo simbólico daqueles que estão na luta pela efetivação de direitos desses docentes? Na tentativa de responder a essa questão principal, organizamos metodologicamente a pesquisa.

\section{Apresentando a investigação}

Como citado, o trabalho cujo foco se dá no desenho metodológico, trata-se de uma pesquisa finalizada em 2017, no doutorado7 em educação, na Universidade Federal de Pernambuco. A partir de constatações de trabalhos anteriores (trabalho de conclusão de curso e mestrado em educação) investigando o mesmo objeto de estudo, violência contra o professor, surgiu a hipótese de que os professores da educação básica deveriam compreender a violência contra eles próprios para além de um fator adverso que leva ao

${ }^{7}$ SOARES, M. B. Violência contra o professor: representações sociais construídas e veiculadas por entidades docentes e seus afiliados. Tese (Doutorado em Educação) - Centro de Educação, Universidade Federal de Pernambuco. Recife, p. 242. 2017.

LUMEN, Recife, v. 28, n. 1, p. 09-27, jan./jun. 2019 
adoecimento do docente, e sim, como um elemento fundamental, articulado à precarização da profissão.

Partimos, ainda, do pressuposto de que o adoecimento dos professores e o descompasso entre as demandas da escola na sociedade atual deveriam fazer parte dos relatos de queixas e insatisfação da categoria docente. Tais queixas provavelmente incluiriam condições degradantes de trabalho, como a desvalorização de salários, a perda de benefícios, o baixo prestígio social da profissão, dentre outros, e isso poderia encontrar respaldo nos movimentos reivindicatórios promovidos pelas entidades sindicais que representam os professores. Portanto, os sujeitos foram escolhidos a partir de suas associações aos sindicatos de professores da Região Nordeste do Brasil, contribuindo, assim, para situar a violência contra o professor através de uma perspectiva individual e de classe profissional.

Dessa forma, buscamos analisar os principais movimentos sindicais de professores da Região Nordeste brasileira, bem como desenvolver um estudo empírico com os docentes associados e dirigentes de instituições sindicais da referida Região.

O embasamento teórico da pesquisa em discussão foi norteado pela Teoria das Representações Sociais (TRS), que também tem um aporte metodológico próprio para as investigações científicas. As representações sociais criam a realidade que, uma vez estabelecida, passa a influenciar as interações sociais e acaba legitimando e justificando condutas. Muitas vezes, essas condutas podem estar a favor de posições ideológicas que contribuiriam para perpetuar o desprestígio da profissão docente e a banalização da violência contra o profissional, pois orientam práticas que materializam esse tipo de violência no cotidiano das pessoas.

Para que um fenômeno se torne uma representação social, é preciso que ele seja objeto de discussão de grupos, gere estranheza ou incômodo. A violência contra o docente se acomoda nessas características e, também por isso, foi tomada como objeto de representação social, uma vez que o fenômeno mexe com o cotidiano e a intimidade das pessoas.

Moscovici também esclarece o que os estudos sobre as representações sociais podem ser capazes de apreender: Como as ideias são transmitidas de geração para geração e comunicadas de um indivíduo a outro? Por que elas mudam o modo de pensar e de agir das pessoas até tornar-se parte integrante de suas vidas? (MOSCOVICI, 1991, p. 77).

Como algo que antes era tão distante da realidade profissional, como sofrer agressão dentro das escolas, agora faz parte de relatos corriqueiros dos docentes? Compreendendo, portanto, a TRS como uma grande teoria, capaz de embasar conceitos indispensáveis para a apreensão dos questionamentos acima propostos, os estudos sobre as representações sociais despontam para paradigmas diferentes, que tomam forma à medida que pesquisadores as particularizam em prol de determinados fins e objetivos.

Sá (2002) sugere três correntes provenientes dos estudos que tomaram como base a original Teoria das Representações Sociais. Essas correntes se desdobram em diferentes perspectivas: a primeira delas se aproxima a aspectos antropológicos, considerada mais próxima à TRS original, proposta por Moscovici. A segunda corrente, liderada por Willem Doise (1990), articula a teoria a uma perspectiva sociológica, enfatizando o contexto e a reprodução da construção da representação num enfoque societal. Por fim, a terceira 
corrente representada por Jean-Claude Abric (1998), chamada Teoria do Núcleo Central, constitui-se como uma teoria complementar à TRS de Moscovici. Esta dá ênfase à estrutura cognitivo-estrutural das representações.

Na perspectiva teórica de Abric (1998), a representação identificada será uma representação partilhada entre os sujeitos do grupo, a partir de elementos comuns. Esses elementos padronizados são constituintes do núcleo central da representação. Com base nessas afirmações, Abric desenvolve uma teoria complementar chamada de Teoria do Núcleo Central, com o objetivo de identificar a constituição das representações sociais através do seu conteúdo e estrutura, para compreender, assim, o seu funcionamento, suas práticas.

Adotamos a abordagem estrutural por considerarmos que captar a estrutura e a organização dos elementos dos subsistemas da representação pode contribuir para compreensão de práticas sociais contra e em prol do professor e de sua profissão. Assumimos também que essa abordagem possibilitaria caracterizar como a violência contra o professor está interligada a outros elementos sociais, através da organização dos componentes da representação, bem como sugerir as relações entre práticas sociais e possíveis transformações.

A partir desta premissa de que a violência contra o professor é um objeto de representação social que guia práticas e se articula com a profissão docente, constituiu-se a pergunta norteadora da investigação: como um fenômeno que tem estado na pauta diária do professor, "violência contra si", povoa o universo simbólico daqueles que estão na luta pela efetivação de direitos desses docentes?

Ainda, se tratando de traçar os caminhos metodológicos, é interessante também retomar os objetivos da pesquisa. $O$ objetivo geral foi compreender as representações sociais da violência contra o professor no espaço das entidades representativas da categoria docente, bem como de professores associados e dirigentes das instituições.

Como objetivos específicos, foram elencados: a) identificar como o fenômeno da violência contra o professor é reconhecido pelas entidades sindicais representativas da categoria; b) conhecer a saliência de representações sociais de violência contra o docente contida nos materiais veiculados por essas entidades; c) identificar a estrutura (núcleo central e sistema periférico) das representações sociais de violência contra o professor de docentes associados às entidades sindicais do Nordeste; d) explicitar como os elementos centrais das representações sociais de violência contra o docente são organizados pelos professores associados a entidades sindicais do Nordeste; e e) caracterizar como a violência contra o professor é representada por professores associados e dirigentes de entidades sindicais nordestinas.

Tendo em vista os objetivos acima explicitados, adotamos uma abordagem qualitativa para a pesquisa, que foi dividida em duas etapas. Reconhecendo a possibilidade da violência contra o docente trazer implicações fundamentais para a prática profissional, partimos para a primeira etapa da pesquisa, um estudo documental, no qual foram analisados textos (estatutos, artigos e notícias) disponibilizados pelos sites das principais entidades sindicais representativas da categoria docente dos nove estados da Região Nordeste, que tratassem do objeto em questão. Na segunda etapa, foi realizado um estudo 
empírico com professores associados e dirigentes das instituições sindicais, com o intuito de apreender as representações sociais de violência contra o docente desse grupo, bem como as articulações desse fenômeno com a precarização da profissão.

Para melhor situar os procedimentos realizados na investigação, segue abaixo um quadro com a síntese do delineamento da pesquisa:

\section{Apresentando a investigação}

\begin{tabular}{|c|c|c|c|c|}
\hline \multirow{2}{*}{ FASES } & \multirow{2}{*}{ OBJETIVO } & \multicolumn{2}{|c|}{ PROCEDIMENTO } & \multirow{2}{*}{$\begin{array}{l}\text { SUJEITOS MATERIAIS } \\
\text { E/OU DOCUMENTOS }\end{array}$} \\
\hline & & Coleta & Análise & \\
\hline \multicolumn{5}{|c|}{ Primeira etapa } \\
\hline \multicolumn{2}{|c|}{$\begin{array}{l}\text { - Identificar como o fenômeno da violên- } \\
\text { cia contra o professor é reconhecido pe- } \\
\text { las entidades sindicais representativas da } \\
\text { categoria; } \\
\text { - Conhecer a saliência das representações } \\
\text { sociais de violência contra o docente con- } \\
\text { tida nos materiais veiculados por essas } \\
\text { entidades. }\end{array}$} & $\begin{array}{c}\text { Análise } \\
\text { Documental }\end{array}$ & $\begin{array}{l}\text { Análise de } \\
\text { Conteúdo }\end{array}$ & $\begin{array}{c}12 \text { estatutos; } \\
30 \text { artigos; } \\
62 \text { notícias. } \\
\text { Total de } 92 \text { documentos }\end{array}$ \\
\hline \multicolumn{5}{|c|}{ Segunda etapa } \\
\hline 1․ fase & $\begin{array}{l}\text { - Identificar a estrutura } \\
\text { (núcleo central e sistema } \\
\text { periférico) das represen- } \\
\text { tações sociais de violência } \\
\text { contra o professor, de do- } \\
\text { centes associados a entida- } \\
\text { des sindicais do Nordeste. }\end{array}$ & $\begin{array}{l}\text { Teste de } \\
\text { Associação } \\
\text { Livre de } \\
\text { Palavras }\end{array}$ & openEvoc ${ }^{8}$ & $\begin{array}{l}420 \text { Professores } \\
\text { associados }\end{array}$ \\
\hline 2a fase & $\begin{array}{l}\text { - Explicitar como os elemen- } \\
\text { tos centrais das represen- } \\
\text { tações sociais de violência } \\
\text { contra o docente são organi- } \\
\text { zados pelos professores asso- } \\
\text { ciados e dirigentes de entida- } \\
\text { des sindicais do Nordeste. }\end{array}$ & $\begin{array}{l}\text { Teste do } \\
\text { Núcleo } \\
\text { Central }\end{array}$ & $\begin{array}{l}\text { Análise de } \\
\text { Conteúdo }\end{array}$ & $\begin{array}{c}18 \text { Professores } \\
\text { diretores e presidentes }\end{array}$ \\
\hline 3a fase & $\begin{array}{l}\text { - Caracterizar como a violên- } \\
\text { cia contra o professor é re- } \\
\text { presentada por professores } \\
\text { associados, dirigentes de en- } \\
\text { tidades sindicais nordestinas. }\end{array}$ & $\begin{array}{c}\text { Entrevistas } \\
\text { semiestru- } \\
\text { turadas }\end{array}$ & $\begin{array}{l}\text { Análise de } \\
\text { Conteúdo }\end{array}$ & $\begin{array}{c}18 \text { Professores } \\
\text { diretores e presidentes }\end{array}$ \\
\hline
\end{tabular}

Fonte: SOARES, 2017.

\footnotetext{
${ }^{8}$ Disponível em:<http://www.hugocristo.com.br/projetos/openevoc/>
} 


\section{Procedimentos de coleta}

Para situar os referidos procedimentos, convém retomar as etapas da investigação que foram dispostas a partir dos objetivos da pesquisa. Balizada pela possibilidade da violência contra o docente trazer implicações para a prática profissional, a primeira etapa da investigação consistiu em uma pesquisa documental, na qual foram analisados 92 (noventa e dois) textos ${ }^{9}$, entre estatutos, artigos e notícias, disponibilizados pelos sites das principais entidades sindicais representativas da categoria docente da Região Nordeste brasileira. A pesquisadora fez um levantamento inicial, em sites de buscas, identificando os sindicatos com maior número de professores associados. Posteriormente, identificou os documentos veiculados pelas instituições em seus sites. O objetivo principal dessa etapa foi compreender como o fenômeno da violência contra o professor era reconhecido pelas entidades sindicais representativas da categoria, e, para isso, identificamos a possível saliência dessa violência contida nos materiais veiculados por essas entidades.

Posteriormente, conforme mostrou o quadro acima, a segunda etapa constituiu-se em três fases:

1a Fase: na primeira fase da segunda etapa, foi realizado um levantamento do conteúdo das representações sociais de 420 professores associados às entidades sindicais em toda Região Nordeste. Os sujeitos participaram de um teste de Associação Livre de Palavras (TALP ${ }^{10}$, objetivando levantar o conteúdo e a possível estrutura interna das representações sociais.

A associação livre é uma técnica baseada na produção verbal dos sujeitos. Por possuir um caráter espontâneo, menos controlado, aliado a uma dimensão projetiva, permite ao pesquisador chegar rapidamente aos elementos que constituem o universo semântico do objeto pesquisado. Tais características fazem com que a associação livre seja considerada adequada para se identificar os elementos constitutivos do conteúdo de uma representação social.

O TALP foi confeccionado na plataforma on-line google.doc, uma ferramenta já conhecida, utilizada para questionários virtuais. $O$ arquivo em questão solicitava, além da caracterização dos sujeitos, como, por exemplo, tempo de serviço e escola em que atuam, que os professores completassem com cinco palavras que lhes viessem imediatamente à lembrança a expressão indutora: Violência contra o professor é... Esse formulário on-line foi divulgado nas redes sociais dos sindicatos, através de um link, com o convite e breve descrição dos objetivos da pesquisa.

O formulário foi disponibilizado por sete meses, entre janeiro e julho de 2016, contando com a adesão total de 453 professores associados. Não se fazia necessário

\footnotetext{
${ }^{9}$ Encontrados a partir dos sites de sindicatos com maior expressividade no Nordeste, ou seja, aqueles com maior número de associados. Foi feita uma primeira triagem nos sites dos sindicatos, localizados a partir de sites de buscas na internet, a fim de selecionar os mais expressivos. Depois, foi feita a categorização dos dados encontrados, tendo em vista o objeto de estudo: violência contra o professor.

${ }^{10}$ Anexo 1.
} 
argumentar sobre as palavras evocadas, nem formular frases. Porém, alguns professores acabaram por formular frases ou não conseguir citar as cinco palavras exigidas. Esses formulários foram desconsiderados, totalizando 420 respostas do TALP válidas. Destacamos, ainda, que o questionário pedia para que os professores selecionassem uma palavra como a que melhor descrevesse o indutor e justificassem a escolha.

É importante ressaltar que as redes sociais foram um grande suporte para engajar os sujeitos a responderem o questionário. Com o auxílio das redes sociais, principalmente do Facebook ${ }^{11}$, os professores foram acionados pelos seus perfis, localizados através das páginas dos sindicatos nordestinos. A pesquisadora lançava chamadas nessas páginas, com o link do questionário, explicando brevemente a pesquisa e pedindo para que os professores, que acessavam as comunidades virtuais vinculadas às entidades sindicais, o respondessem. Depois, visitava o perfil de alguns desses docentes mais atuantes e enviava mensagens privadas, solicitando que respondessem à pesquisa. Isso colaborou para que tivéssemos um bom número de respostas.

Após isto, as evocações dos sujeitos foram incluídas em uma plataforma on-line chamada openEvoc. Esse aplicativo, criado por Sant'Anna (2012), além de promover outras ferramentas para categorização de dados, baseia-se em um software comumente utilizado para tratamento de resultados da associação livre em representações sociais, o software Ensemble de Programmes Permettant l'Analyse des Evocations (EVOC, 1999) ${ }^{12}$. O aplicativo permitiu organizar os elementos evocados pelos professores, identificando a estrutura geral da representação, o possível núcleo central e as periferias.

2a) Fase: na segunda fase, participaram 18 (dezoito) professores, entre diretores e presidentes de sindicatos nordestinos. Utilizamos outro procedimento associativo que consistiu em um teste do núcleo central, inspirado nas Triagens Hierarquizadas Sucessi$\operatorname{vas}^{13}$ (ABRIC, 1998), cuja finalidade foi corroborar quais elementos efetivamente estruturaram o núcleo central das representações, utilizando as cognições correspondentes identificadas na fase anterior.

Os termos foram apresentados aos sujeitos num processo de seleção contínua e orientações fornecidas pela pesquisadora. Os sujeitos dessa segunda fase foram escolhidos por estarem vinculados ativamente aos sindicatos do Nordeste: Alagoas - SINTEAL; Bahia APBLSindicato; Ceará - APEOC; Maranhão - SINPROESEMMA; Paraíba - SINTEPPB; Pernambuco - SINPRO-PE; Piauí - SINTEPI; Rio Grande do Norte - SINTERN; Sergipe - SINTESE.

Esse teste foi realizado através de uma chamada de vídeo em que a pesquisadora mostrava fichas contendo as palavras que poderiam indicar centralidade. A técnica foi

\footnotetext{
${ }^{11}$ Facebook é uma rede social lançada em 4 de fevereiro de 2004, operado e de propriedade privada da Facebook Inc. Em 4 de outubro de 2012, o Facebook atingiu a marca de 1 bilhão de usuários ativos, tornando-se a maior rede social de todo o mundo (Fonte: Internet).

${ }^{12} \mathrm{O}$ software Ensemble de Programmes Permettant l'Analyse des Evocations (EVOC) foi construído por Pierre Vergès, em 1999. Constitui um conjunto de programas que permitem a análise de evocações da associação livre.

${ }^{13}$ Anexo 2
}

LUMEN, Recife, v. 28, n. 1, p. 09-27, jan./jun. 2019 
aplicada por meio de chamada de vídeo, no aplicativo WhatsApp, o áudio foi gravado e posteriormente transcrito.

3a) Fase: finalizando o estudo, foram realizadas entrevistas semiestruturadas ${ }^{14} \mathrm{com}$ 24 membros, entre diretores sindicais e presidentes. Planejamos, inicialmente, realizá-las diretamente com esses sujeitos, no entanto, devido à dificuldade de acesso a esses profissionais, optamos por 18 (dezoito) entrevistas on-line e 06 (seis) presenciais.

No caso desta investigação, tanto nas entrevistas on-line quanto presenciais, os sujeitos foram indagados com base em um roteiro que abordava os seguintes pontos: as causas da violência contra o docente; manifestações de violência contra o professor que já tiveram contato; atitudes de enfrentamento para com essa violência e o papel do sindicato dos professores no combate a esse tipo de violência. O objetivo foi que os resultados permitissem aprofundar as informações sobre as crenças, atitudes e percepções do grupo em relação ao objeto focalizado.

Primeiramente, realizamos as entrevistas on-line. Utilizando a mesma ferramenta, tais entrevistas foram realizadas por meio de chamada de vídeo no aplicativo WhatsApp. 0 áudio foi gravado e posteriormente transcrito. Destacamos mais uma vez que a tentativa de abrangência de toda a Região Nordeste e a dificuldade de acesso a todos os sujeitos in loco justificaram a utilização de meios on-line para a coleta desses dados.

Cabe enfatizar que o avanço das tecnologias da informação e comunicação tem permitido aos pesquisadores inovar metodologicamente e desenvolver pesquisas por novos meios. Na maioria das vezes, os investigadores utilizam técnicas e métodos de pesquisa tradicionais no ambiente virtual, como o caso desta pesquisa - as entrevistas semiestruturadas foram realizadas por meio de uma chamada em que pesquisador e entrevistado conversavam em tempo real, através de um smartphone.

\footnotetext{
Os mundos, online e off-line, não são necessariamente realidades separadas - mundo real versus mundo virtual - mas podem ser considerados um continuum da mesma realidade. De tal forma, o pesquisador deve desenvolver técnicas que o permita analisar esse continuum. Nesse sentido, é interessante notar que, dentre as comunidades ou os grupos que um pesquisador viria a estudar, pode-se destacar os puramente virtuais, ou seja, que são socialmente criadas no ambiente virtual; as que são construídas tanto online quanto off-line; e as que são construídas puramente off-line, ou seja, no ambiente físico (NOVELI, 2010, p. 109).
}

Após a realização das entrevistas on-line, em um segundo momento, um mês depois das primeiras, a pesquisadora realizou outras 06 (seis) entrevistas presenciais com diretores e presidentes de sindicatos de três estados nordestinos - Pernambuco, Paraíba e Rio Grande do Norte. Essas entrevistas seguiram o mesmo roteiro semiestruturado das primeiras e esses estados foram escolhidos devido à localização geográfica e pronta adesão dos participantes à investigação em questão. Para agendá-las, a pesquisadora entrou em contato com os sindicatos via telefone e explicou brevemente os objetivos da

\footnotetext{
${ }^{14}$ Anexo 3.
} 
pesquisa. As entrevistas presenciais foram gravadas em áudio, duraram em torno de uma hora e foram posteriormente transcritas.

As informações coletadas seguiram na mesma direção das entrevistas já realizadas por meio virtual: os docentes se colocaram principalmente em relação à violência sofrida pelos professores, seus modos e origens e o papel do sindicato em que atuavam. De maneira geral, as entrevistas não tiveram dissonâncias, porém, a aproximação direta permitiu que os sujeitos se colocassem mais à vontade sobre questões políticas e governamentais das localidades nas quais eles atuavam, além de situarem mais especificamente a violência contra os docentes e a violência social enfrentada nos estados em que residiam.

\section{Discutindo a coleta de dados on-line}

Como indicado, foram utilizados procedimentos que indicam a adoção de uma abordagem plurimetodológica: análise documental, um teste de Associação Livre de Palavras, um teste do núcleo central e entrevistas semiestruturadas. Cabe ressaltar novamente que a coleta de dados da pesquisa em questão foi realizada tanto de maneira presencial, quanto através de ambientes virtuais on-line (sites, rede social Facebook, aplicativo WhatsApp e a plataforma google doc.), porém, predominando o auxílio da internet.

É inegável que esse tipo de conexão passou a integrar a vida das pessoas e que grande parte das conversas cotidianas, divulgação de textos informais e acadêmicos e notícias de maneira geral são feitas através de trocas de mensagens instantâneas, de e-mails ou de plataformas on-line. Logo, a internet vem se afirmando como um grande meio de comunicação de massa, que integra pessoas do mundo todo, passível de ser submetido a procedimentos metodológicos fidedignos de pesquisas (NOVELI, 2010).

Nessas investigações, geralmente os instrumentos já tradicionais em investigações de contato direto com os sujeitos, como entrevistas e questionários, são reorganizados para se adequarem ao ambiente virtual. Costa, Dias e Luccio (2009), por exemplo, discutem sobre o uso de entrevistas on-line no Método de Explicitação do Discurso Subjacente (MEDS). No referido artigo, as autoras afirmam que a coleta de dados por meio de entrevistas virtuais vem se afirmando como um procedimento de pesquisa sério e viável. Inclusive, algumas áreas de conhecimento, como o marketing, já utilizam ferramentas on-line para coletar dados de suas pesquisas de maneira mais recorrente.

Porém, algumas especificidades devem ser levadas em consideração, como deixar claro o público-alvo ou estabelecer critérios para os sujeitos da pesquisa, visto que um questionário on-line pode ser respondido por pessoas que podem não se adequar ao objetivo do pesquisador. Além disso, é necessário procurar desenvolver estratégias para garantir a fidedignidade dos dados obtidos, dentre outras ações.

Ainda, Daniel Gonçalves (2008) aborda em seu estudo vantagens e desvantagens da utilização de métodos on-line de coleta de dados em pesquisas qualitativas. Como algumas vantagens da utilização de meios digitais, Gonçalves (2008) aponta para o grande 
alcance global da internet, que torna possível a coleta de informações de indivíduos localizados em diferentes regiões de um mesmo país, ou em diferentes áreas do mundo.

$\mathrm{O}$ autor ainda considera a flexibilidade, pois as pesquisas podem ser realizadas em diversos formatos: e-mails com questionários anexados; e-mails com links (URL); convites feitos a internautas por meio de um website, etc. Inclusive, em mais de um idioma. $\mathrm{O}$ terceiro ponto levantado pelo autor é a economia, visto que pesquisas pela internet reduzem o tempo gasto com o trabalho de campo e coleta dos dados. A quarta vantagem são as inovações metodológicas - os investigadores têm de adaptar os instrumentos ao ambiente virtual, e a velocidade - os dados permitidos pela internet garantem o acesso em tempo real a informações e dados de grupos de respondentes geograficamente dispersos.

O último aspecto levantado trata do controle da ordem de perguntas respondidas e obrigatoriedade das respostas, já que as pesquisas on-line garantem o controle sobre quais perguntas os entrevistados devem responder, ao mesmo tempo que determinam e garantem a ordem adequada para o preenchimento destas. $O$ autor também elenca uma série de pesquisadores que discutem sobre essa possibilidade metodológica: SCHOLL, MULDERS e DRENT, 2002; EVANS, MATHUR, 2005; e MALHOTRA, 2004 (GONÇALVES, 2008, p. 74).

Apesar de todos esses benefícios, Gonçalves pondera sobre as desvantagens de realizar esse tipo de coleta, como, por exemplo, os questionários podem ser recebidos como SPAM (lixo eletrônico), afetando a credibilidade e o percentual de respostas obtidas. 0 pesquisador também deve considerar a falta de habilidade dos respondentes, já que alguns indivíduos podem não estar familiarizados com algumas funções características do ambiente virtual. Além disso, a impessoalidade pode trazer dificuldades para aprofundar os dados coletados. Em algumas ocasiões, ocorrem baixas taxas de resposta, considerada como a principal desvantagem associada à realização de uma pesquisa pela internet, seja pela inadequação do instrumento, seja pela falta de interesse dos sujeitos sobre o tema pesquisado (GONÇALVES, 2008).

Portanto, é importante que o pesquisador pondere sobre essas questões antes de submeter instrumentos on-line para a coleta de dados de sua pesquisa, ressaltando que a interferência e a organização prévia de quem investiga é fundamental para o sucesso da coleta.

Na investigação em questão, por exemplo, na etapa da pesquisa documental, o acesso aos sites das instituições foi simples. A pesquisadora localizou os sindicatos nordestinos nas plataformas usuais de buscas. O documento disponibilizado no google.doc, na segunda etapa da pesquisa, teve a adesão de 420 professores da Região Nordeste, possibilitando a caracterização estrutural da violência contra o docente, bem como o teste de centralidade do núcleo. Isto só foi possível pela intervenção e constante divulgação da pesquisadora em redes sociais que tratavam especificamente da temática.

É importante destacar que as entrevistas com os professores membros da direção dos sindicatos que residiam nos estados mais distantes de Pernambuco só foram possíveis de serem realizadas mediante o uso de uma ferramenta virtual, uma vez que, além da distância geográfica, era difícil conciliar a agenda dos dirigentes sindicais com a 
disponibilidade para participar da pesquisa. Como desvantagens do recurso, aponta-se a dificuldade em localizar os professores para as últimas fases da pesquisa, bem como conseguir um maior número de docentes disponíveis para conceder as entrevistas.

Sobre o uso da internet como uma ferramenta possível para coleta de dados, cabe lembrar que sua utilização já é comum nas pesquisas do tipo estado da arte. As revisões sistemáticas de literatura (que lidam com material bibliográfico) têm sido realizadas nos ambientes virtuais com frequência cada vez maior (FERREIRA, 2002). A internet se afirma como aliada nas buscas desse tipo de pesquisa, pois permite que o pesquisador encontre seus dados de maneira rápida e com baixo custo, facilitando o acesso a diversos tipos de documentos em todo território nacional e, inclusive, às produções internacionais. Cada vez mais, as plataformas on-line que armazenam teses, dissertações, artigos em periódicos, trabalhos de conclusão de cursos estão presentes na vida acadêmica dos pesquisadores.

Sendo assim, pode-se afirmar que recolher dados por essa via não causa tanta estranheza. No caso deste estudo, existia a dificuldade de acessar diretamente os sujeitos para obter informações, e a intenção de abranger uma das maiores regiões do Brasil. Portanto, a possibilidade de se utilizar os ambientes virtuais como campo para coletas de dados é viável, inclusive, em pesquisas em educação, desde que esteja articulada aos objetivos e à intencionalidade do pesquisador.

\section{Considerações finais}

Para qualquer alternativa metodológica, é preciso estar seguro a respeito do motivo das escolhas que se faz, bem como sobre as vantagens e desvantagens das opções adotadas. A internet vem se afirmando como parte da vida das pessoas e é compreensível que seja também passível de ser submetida a pesquisas acadêmicas, geralmente a partir de instrumentos de coletas já tradicionais reorganizados para se adequarem ao ambiente virtual.

As vantagens de utilizar esse meio são muitas, com ênfase para a possibilidade de coletar informações de indivíduos localizados em diferentes regiões, a flexibilidade, a economia, o controle do tempo e, ainda, a possibilidade de criar estratégias para fazer pesquisas. As desvantagens estão na probabilidade de os questionários chegarem como lixo eletrônico para os sujeitos, na falta de habilidade dos respondentes e, principalmente, na impessoalidade que pode trazer dificuldades para o aprofundamento dos dados coletados.

Reiteramos que, com o auxílio das redes sociais, principalmente do Facebook, o interesse dos docentes em responder foi muito expressivo. Os participantes tiveram uma participação ativa nas respostas, inclusive deixaram comentários sobre a importância da pesquisa e a invisibilidade social do objeto pesquisado - violência contra o professor. Portanto, o pesquisador deve pensar em estratégias para uma coleta eficiente. A atenção dada nesse momento faz a diferença, nas pesquisas in loco e, principalmente, nos ambientes virtuais.

Nessa experiência, percebemos que o investigador tem que instigar e cativar ainda mais os sujeitos, para que tenham interesse em participar da investigação, evitando a 
dispersão, possível fuga ao tema, e tendo que driblar possíveis problemas na rede (internet). 0 pesquisador pode, inclusive, utilizar a flexibilidade da coleta on-line, em seu favor e dos sujeitos: se adequar aos horários dos participantes, possibilitando que estes participem com comodidade e conforto.

É importante destacar também o uso de aplicativos como um recurso eficiente para a coleta. As entrevistas on-line, por exemplo, foram desenvolvidas por meio de chamada de vídeo pelo WhatsApp, um aplicativo gratuito e popular. Isso demonstra que o pesquisador deve ter em mente o problema de pesquisa e seus objetivos para o desenvolvimento de estratégias que sejam viáveis para os participantes. Cabe destacar que as entrevistas, tanto através da internet quanto presenciais, não tiveram dissonâncias. Este é um ponto positivo, que demonstra a capacidade de coleta de dados coerentes também nesses ambientes. Os dados colhidos através dos ambientes virtuais on-line não foram insuficientes em relação aos dados coletados in loco.

Assim, reiteramos a possibilidade de coletar dados fidedignos através da internet, visto que a pertinência das opções metodológicas está intrinsicamente atrelada à questão de pesquisa, aos objetivos elencados pelo pesquisador e ao modelo teórico escolhido. Afirmamos que, no caso dessa investigação, a coleta de dados através de ambientes virtuais ofereceu mais vantagens que desvantagens, e pode ser uma possibilidade para outras pesquisas, tudo dependerá do modo como a investigação for desenvolvida.

\section{Referências}

ABRIC, J. C. A abordagem estrutural das representações sociais. In: MOREIRA, Antônia Silva Paredes; OLIVEIRA, Denize Cristina de. (Orgs.) Estudos interdisciplinares de representação social. Goiânia: $A B, 1998$. p. 27-38

COSTA, A. M. N. da; DIAS, D. R.; LUCCIO, F. D. Uso de entrevistas on-line no método de explicitação do discurso subjacente (MEDS). Psicol. Reflex. e Crít. Porto Alegre. v. 22, n. 1, 2009. DOISE, W. Les représentations sociales. In: GHIGLIONE, C. B.; RICHARD, J. P. (Orgs.) Traité de psychologie cognitive. Paris: Dunod, 1990

EVANS, Joel R.; MATHUR, A. The value of online survey. Emerald Publishing, v. 15, n. 2, p. 195-219, 2005.

FERREIRA, N. S. de A. As pesquisas denominadas "estado da arte". Educ. Soc. [online]. v. 23, n. 79, p.257-272, 2002.

GONÇALVES, D. I. F. Pesquisas de marketing pela internet: as percepções sob a ótica dos entrevistados. Revista de Administração Mackenzie, v. 9, n. 7, nov./dez. 2008.

MALHOTRA, N. Pesquisa de marketing: uma orientação aplicada. 3. ed. Porto Alegre: Bookman, 2004.

MINAYO, M. C. de S. et al. (Org.) Pesquisa social: teoria, método e criatividade. 19. ed. Petrópolis: Vozes, 2001.

MOSCOVICI, S., DOISE, W. Dissensões e consenso: uma teoria geral das decisões coletivas. Lisboa: Horizonte, 1991 
NOVELI, M. Do off-line para o online: a netnografia como um método de pesquisa ou o que pode acontecer quando tentamos levar a etnografia para a Internet?. Organizações em Contexto, a. 6, n. 12, jul-dez/2010

SÁ, C. P. de. Núcleo central das representações sociais. 2. ed. Petrópolis: Vozes, 2002.

SANT'ANNA, H.C. OpenEvoc: um programa de apoio à pesquisa em representações sociais. In: ENCONTRO REGIONAL DA ABRAPSO, 7, 2012, Vitória, ES. Anais eletrônicos. Vitória, 2012.

SOARES, M.B. Violência contra o professor: representações sociais construídas e veiculadas por entidades docentes e seus afiliados. 242 f. 2017. Tese (Doutorado em Educação) - Universidade Federal de Pernambuco. Recife, 2017.

SCHOLL, N.; MULDERS, S.; DRENT, R. Online qualitative market research: interviewing the at a fingertip. Qualitative Market Research, 2002. 


\section{ANEXO 1 - Teste de Associação Livre de Palavras}

Título da pesquisa: VIOLÊNCIA CONTRA O PROFESSOR: REPRESENTAÇÕES SOCIAIS CONSTRUÍDAS E VEICULADAS POR ENTIDADES DOCENTES E SEUS AFILIADOS

Pesquisa realizada na Universidade Federal de Pernambuco sobre a violência contra o professor na Região Nordeste.

Doutoranda: Michelle Beltrão Soares

Sexo
$($ ) Feminino ( ) Masculino

\section{Formação acadêmica}

( ) Pedagogia ( ) Licenciaturas diversas

Nível de formação acadêmica

( ) Graduação ( ) Especialização ( ) Mestrado （ ) Doutorado

\section{Estado em que trabalha}

$\begin{array}{lllll}\text { ( ) Alagoas } & (\text { ) Bahia } & (\text { ) Ceará } & (\text { ) Maranhão } & (\text { ) Paraíba } \\ \text { ( ) Pernambuco } & (\text { ) Piauí } & (\text { ) Rio Grande do Norte } & (\text { ) Sergipe }\end{array}$

\section{Rede em que atua}

( ) Municipal ( ) Estadual

\section{Atuação profissional}

$\begin{array}{ll}\text { ( ) Educação Infantil } & \text { ( ) Ensino Fundamental I } \\ \text { ( ) Ensino Fundamental II } & (\text { ) Ensino Médio }\end{array}$

\section{Tempo de atuação como professor}
( ) 0 a 5 anos
( ) 5 a 10 anos
( ) 10 a 15 anos
( ) mais de 15 anos

Escreva as cinco primeiras palavras que the vêm imediatamente à lembrança quando pensa em: Violência contra o professor.

Organize as cinco palavras citadas anteriormente em ordem hierárquica, onde a primeira é a mais importante quando você pensa na violência contra o professor.

Dentre as cinco palavras anteriormente escritas, escolha a mais importante. Justifique a sua resposta.

Never submit passwords through Google Forms.

This content is neither created nor endorsed by Google. Report Abuse - Terms of Service - Additional Terms

LUMEN, Recife, v. 28, n. 1, p. 09-27, jan./jun. 2019 
ANEXO 2 - Cartelas com termos para realização do Teste do núcleo central (triagens)

Título da pesquisa: VIOLÊNCIA CONTRA O PROFESSOR: REPRESENTAÇÕES SOCIAIS CONSTRUÍDAS E VEICULADAS POR ENTIDADES DOCENTES E SEUS AFILIADOS

Pesquisa realizada na Universidade Federal de Pernambuco sobre a violência contra o professor na Região Nordeste. Doutoranda: Michelle Beltrão Soares

\section{DESRESPEITO}

\section{IMPUNIDADE}

\section{AGRESSÃO}

\section{DESVALORIZAÇÃO}

\section{FAMÍLIA}

\section{PALAVRÃO}

RESPEITO

\section{EDUCAÇÃO}




\section{ANEXO 3 - Roteiro de entrevista semiestrutura}

Título da pesquisa: VIOLÊNCIA CONTRA O PROFESSOR: REPRESENTAÇÕES SOCIAIS CONSTRUÍDAS E VEICULADAS POR ENTIDADES DOCENTES E SEUS AFILIADOS

Pesquisa realizada na Universidade Federal de Pernambuco sobre a violência contra o professor na Região Nordeste.

Doutoranda: Michelle Beltrão Soares

- Causas da violência contra o professor;

- Manifestações de violência contra o docente o sujeito conhece ou teve contato;

- Frequência desses casos;

- Atitudes de enfrentamento contra essa violência por parte dele próprio ou teve contato;

- Papel do sindicato dos professores do estado do sujeito em relação à violência contra o docente;

- Exemplos de como o seu sindicato atua nesses casos.

Recebido em: 11.05.2019

Aprovado em: 17.05.2019

\section{Para referenciar este texto:}

SOARES, Michelle Beltrão; MACHADO, Laêda Bezerra. Coleta de dados em ambientes virtuais: uma possibilidade para as pesquisas em educação. Lumen, Recife, v. 28, n. 1, p. 09-27, jan./jun. 2019. 